It is especially urged that all chemists who intend visiting the World's Fair take this occasion to do so, by which they can combine the pleasure of visiting the Exposition with the benefit derived from attendance at the congress. To American chemists an especial appeal is made to be present for the purpose of welcoming our foreign visitors and showing them the progress of chemical science in the United States.

HARVEY W. WILEY.

\section{THE EFFECT OF FOOD UPON THE COMPOSITION OF BUT-} TER.

BY FRED W. MORSE, DURHAM, NEW HAMPSHIRE.

Practical dairymen, who produce a high grade of butter, lay great stress upon the quality of food with which their cows are fed. Chemists, who have had much to do in the examination of butter for adulterants, have observed that the samples from one region have steadily varied in their composition from those of another region, where different practice prevailed in feeding. These facts have led to many experiments, both in Europe and America, to find out the specific action of different foods upon the composition of butter.

This product of the dairy is composed of fat, water, salt and curd; and of these, the cow is responsible for only the fat and the curd. The former constitutes about eighty-five per cent and the latter barely one per cent of the butter, therefore chemical examinations for variations due to food have been confined wholly to the fat. Butter-fat differs from the fat deposited in the body of the animal by having from five to seven per cent of volatile fatty acids, and only eighty-seven to ninety per cent of insoluble, fatty acids, while tallow has ninety-five per cent of the latter and less than one-half of one per cent of the former. The volatile acids give butter fat its characteristic flavor, and also cause it to be softer than tallow. Butter fat also differs from tallow in having less oleic acid among its insoluble acids. These two characteristics of butter-fat have been studied more than any of its other properties, because of their relations to adulterations, and the studies of food effects have so far been confined to the same lines.

In the course of investigations, it has been found that in general, the widest variations in volatile acids and oleic acid are due to the progress of lactation, the latter increases and the former decrease as the period advances. Individual cows also vary widely from one another in the composition of their butter fat, but with regard to the breeds, no definite conclusions can be made.

The effect of food is greater upon the oleic acid than upon the volatile acids and, in nearly all cases, variations in this constituent of the fat have been closely related to variations in the firmness of the butter. This is to be expected, as oleic acid is an oily liquid at summer temperature, and the butter is 'softer or harder as this acid is present in greater or less amount.

Many of the foods have been tried in such limited amounts that it is unsafe to draw conclusions, therefore only such foods will be mentioned here as have been used in repeated trials. The most notable effect has been produced by cotton-seed and cuttonseed cake. Whenever it has been fed, the volatile acids and oleic acid have been depressed below the average; the butter is deficient in flavor and often too hard to be easily cut with a knife.

In strong contrast to this action of cotton-seed, is the effect of gluten-meal, a by-product from the manufacture of corn-starch. This food is especially effective in raising the oleic acid above the average, and also produces a butter-fat high in volatile acids. The butter from this food is frequently too soft for an ideal product. Corn-meal, however, has always produced a butter-fat low in oleic acid, but has shown no action on the volatile acids. Clover, dry or green, has produced fat high in volatile acids, and with oleic acid slightly above the a verage. The same is also true of spring pasturage. Early cut straw generally produces a fat with volatile acids and oleic acid below the average.

The action of clover and pasturage in increasing the volatile acids, and that of corn in lowering the oleic acid, explains the practice of the makers of first-class butter, who rely upon these foods to produce a good flavor and firm grain.

\section{ELECTRICAL NOTES.}

THE present Electrical Exhibit at the World's Fair contains much more that is of interest from an engineering standpoint than from a purely scientific one. Magnificent as the engineering display is, there is little that is new. Everything is now thoroughly mechanical, one no longer sees the monuments of tortured ingenuity which used to pervade the former exhibitions; in its place are the results of sound and competent engineering skill.

The multipolar machine has evidently come to stay. Three years ago there was not, I believe, a single large multipolar machine made. Almost the only makers of machines above 100 horse-power were the Edison, Brush, and Westinghouse Companies (we are speaking of America, of course; on the Continent of Europe multipolar machines have been the rule), and their machines were all bipolar. Now there is on exhibit hardly a single machine above 50 horse-power which is not multipolar. Splendid examples of these are the Westinghouse, Thomson-Houston, and Edison direct connected generators.

The general use of the toothed armature is also a new feature. A short time ago the hardy individual who should have proposed designing a large dynamo with toothed armature would have been told that it was impossible to do it, that the consequent increase of self-induction would make it spark so badly that it could not be run, that the only way to make a dynamo whose brushes would not need sbifting between full and no load was to have a big air-gap, and all this would have been backed up by alarming mathematical quotations from Ayrton and other writers.

Now we see that the impossible way is the only way, and the designer who neglects the aid of the toothed armature is handicapping himself very much. In passing, one may notice that, if one may judge from several recently-read papers in the English Institute of Electrical Engineers, European designers are not able as yet to design a toothed armature which shall not spark, shall require no shifting of brushes, and shall be highly efficient. Even the machines, which probably furnished the encouragement to American designers to try the toothed armature, i.e., the Brown machines for electro-metallurgy, we learn, recently, had to be sent back to the factory, the armature turned down, and rewound with an exterior winding.

A mong the new things in engineering, the large two-phase 1,000 horse-power generators of the Westinghouse Company deserve especial attention. The large amount of work now being done in this line by the various companies is a good augury for the rapid development of the system. If this proves a success, the days of the continuous current will be ended, so far as engineering is concerned. There are three things so far which bave hampered the alternating current: (1) Poor all-day efficiency of transformers, (2) noisy arc-lights, and (3) absence of motors. The recent developments in transformer design have resulted in transformers with an all-day efficiency of 94 per cent; the new lowpotential arc-lamps give a better light than the continuous-current lamps, and as noiseless; and there only remains the development of the motor system, which now seems to be within sight.

Electric welding is evidently no longer a thing of the future. There are a number of firms making displays, who are using the Thomson process in their business. Several of the wagon-making firms use the welders to make tires and weld axles; wire-making companies use them to join lengths of wire; they are used in making shells for modern machine and quick-firing guns; for joining up lengths of pipe in ammonia ice-machines; and for welding rails together to form a continuous track. This last is a most interesting exhibit, as, if successful in practice, it will lead to a new method of railway construction, for street railways at least. A track has been in operation for some time near the ThomsonHouston factory in Lynn, and the results seem to have been very good. No trouble was experience from expansion or contraction, the friction of the rails in the ground preventing displacement and creeping, and the expansion merely manifesting itself as a stress in the rails, well within the elastic limit.

Among recent practical applications of electricity are the electric chimes and tower-clock system, now on exhibition in the tower in the centre of the Manufactures and Liberal Arts Building. These are the invention of Mr. Attwood, and the chimes have been used for 